\title{
The research of intelligent substation project management mode based on RFID
}

\author{
Chenglei Sun ${ }^{1,2, a}$, Ke Zhang ${ }^{1, b}$, Baojian Zhao ${ }^{2, c}$ and Ting Zhang ${ }^{2, d}$ \\ ${ }^{1}$ School of Economic and Management, North China Electric Power University, Beijing 102206, \\ China; \\ ${ }^{2}$ Jinzhou Electric Power Supply Company, State Grid Liaoning Electric Power Supply Co. Ltd, \\ Jinzhou 121001, China. \\ a277129298@qq.com, b798088804@qq.com, 'czhaobaojian@21cn.com, 'ztdazgbt@163.com
}

Keywords: Intelligent substation, Joint debugging, RFID, life-cycle management.

\begin{abstract}
Intelligent substation system joint debugging is the key link in the course of the construction of intelligent substation, this paper puts forward the lifecycle management model based on the RFID information integration. Together with the present situation of intelligent substation system joint debugging stage management, management mode to the application of the premise, the key points of the organizational structure, the specific operating points of tripartite face based on RFID information integration comprehensive explanation of the implementation of the whole life management mode. Through the analysis of the effect of optimal management, showing the feasibility of optimization management. For the future intelligent substation system joint debugging project management model to provide the reference.
\end{abstract}

\section{Introduction}

With the progress of science and technology and the development of the society, human engaged in engineering construction, scientific research and development, environmental transformation and other activities more and more complex, the importance of project management in the whole activity also will increase. [1,2]

Project management theory has been widely used in intelligent substation commissioning projects, but as a result of intelligent substation belongs to the emerging technology and equipment, management standard has not yet been forming, the debugging also have a lot of problems in project management, the traditional substation debugging management mode to take a lot of human resources, gradually cannot meet the needs of the network rapid development, in line with the development of the smart grid construction, earnestly implement the needs of the rapid development of national power grid, change the way of promoting the development of power grid, the existing debugging management pattern already cannot adapt to the need of its development, solve the problems existing in the existing management mode, to adapt to the new smart substation operations alignment stage project management pattern research and the building is imminent. $[3,4]$

The purpose of this paper is to through the actual investigation and study of Liaoning power grid intelligent substation joint debug mode in Jinzhou area present situation, combining the theory of organization structure change and technological innovation, the RFID technology and the concept of whole life cycle management mode, to construct the intelligent substation operations joint debugging stage management model, to improve the level of intelligent substation joint debugging stage management, intelligent substation joint debugging period, save manpower and material resources, enhances the working efficiency of the joint debugging stage, Jinzhou area as intelligent substation joint debugging operations management to bring good economic and social benefits. 


\section{The RFID technology in whole life cycle of information integration of power equipment management}

\subsection{Summary of RFID}

RFID (Radio Frequency Identification), is a kind of communication technology, mainly composed of an electronic tag, reader, middleware, software system of four parts. [5,6] RFID technology can by radio signal to replace the original mechanical or optical contact method to identify specific targets and to read and write the related data, make the information easier to read and write. [7] Because of the RFID technology is more than a lot of advantage (as shown in table 1), RFID technology is widely used in logistics, transportation, factory management, library management, entrance guard system, food safety traceability, etc.

Table 1 RFID Compared with traditional information record information recording process Traditional information recording Based on the RFID information recording process process

Record mode Transcript, Camera monitored, Bar code etc.

Advantage The early stage of the less equipment investment

1. Good penetrability, not affected by covered shelter

2. Pollution resistance and good durability, can be repeated use

3. Data storage security and stability

4. Read and write is rapid, low error probability

5. The human cost is low

Disadvantage 1. Low efficiency

2. Easily affected by environmental Early needs certain investment of equipment and high factors cost

3. Spend a lot of manpower

4. A higher probability of error

5. The data is lost easily

To realize the integration of the power equipment based on RFID technology, information, hardware to include RFID tags, handheld PDA, speaking, reading and writing device host, data transmission network, and the background.

2.2 The RFID information integration management of whole life cycle of electrical equipment Power equipment of the whole life cycle management, overall process is as follows: in the electric power equipment assets are installed on the RFID tags, tags recorded in the corresponding equipment manufacturers, specifications, products factory number, time, equipment assets registration number, opening time, use the information such as location, belonging to the unit, the safety supervision responsibility, as a device ID, convenient for inspection and acceptance of equipment in the units they belong to, inventory management, inspection, maintenance, retired scrap operation stage to implement real-time intelligent monitoring.[8] Its whole life-cycle management process in figure 1.

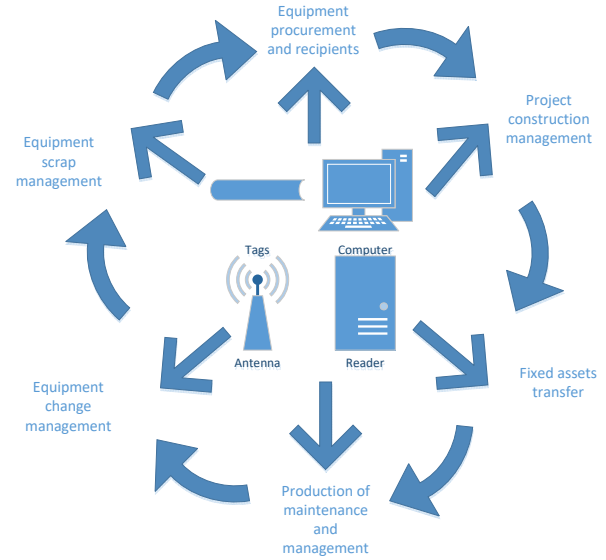

Fig.1 Equipment management in whole life-cycle based on RFID 


\section{The RFID joint debugging information integration project management}

\subsection{Management mode application premise}

Regulations, standards and regulations formulation is management mode to be able to play a role and the prerequisite of successful application. Intelligent substation debugging project as a new and high technology project, the relevant standards is not perfect, at present, no supervision and intelligent substation debugging project carried out strict standards, standards is imminent.[9]

(1) The supervision and management system. In the process of intelligent substation equipment is not present in time, the debugging process are too formal, cannot achieve the phenomenon such as joint debugging purposes are intelligent substation joint debugging stage the importance of supervision and management system. In the system, should be clearly stipulated in the process of intelligent substation system joint debugging and responsibilities clear, punishment standard, etc.;

(2) The intelligent substation system joint debugging project acceptance standards. In joint debugging test, the manufacturer's personnel for the purpose of equipment can normal operation, the state grid related technical personnel have no core technology, said only in strict accordance with the technical specifications for debugging work, the final debugging results without a specific set of files, lead to technical personnel rush it, therefore, intelligent substation joint debugging project acceptance criteria is the guarantee for establishing the joint debugging to ensure;

(3) Technical personnel eligibility standards. Because of debugging technology mainly in the hands of intelligent equipment provider, sent by the makers of technical personnel technical level is crucial, so choose to meet the requirements of intelligent substation debugging technique level technical personnel is the important guarantee of commissioning quality and progress.

\subsection{Organization points}

In smart substation base debugging, staff involved in the joint debugging project for intelligent substation intelligent equipment providers and technical personnel, construction technical personnel and substation maintenance company technical personnel even more participants, how to coordinate several parties to participate in the work, and clear responsibilities and rights of the parties is critical, so a clear organization structure is the first condition of work.[10] This article USES the linear function type organizational structure, as shown in figure 2.

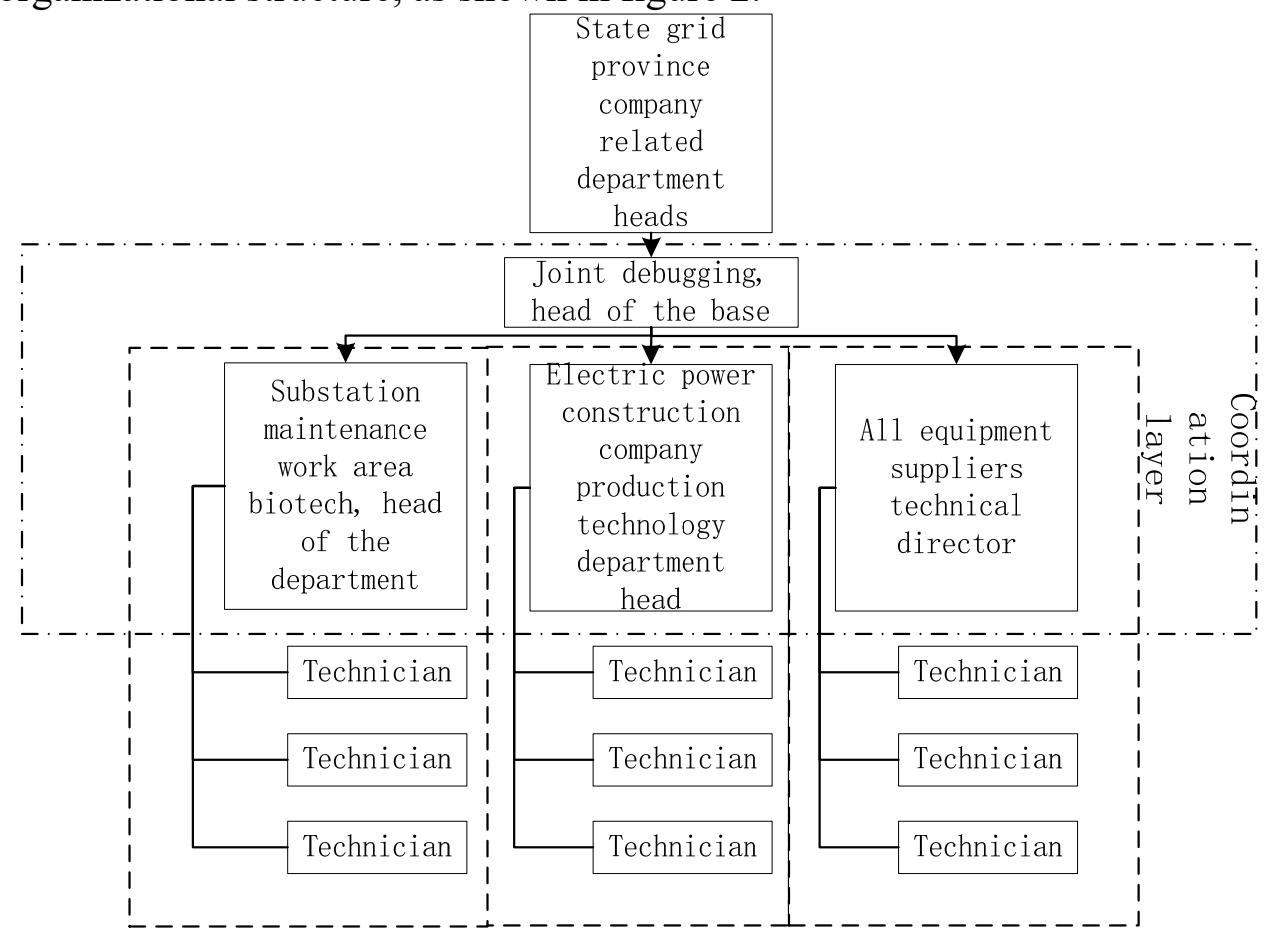

Fig.2 Organization chart 
By figure 2 can be clearly shows that in intelligent substation base joint debugging management mode should be set up joint debugging project director, responsible for coordinating the whole project, including the coordination of the parties. The parties have set their base and joint debugging direct communication technical director, project manager, responsible for transmission on the head and base coordinate into the base time, task allocation, real time schedule, etc. to convey to the accompanying technical staff under the task allocation, technical requirements, etc.

Head of the base with the participants, head of technology of project coordination group, is responsible for the coordination of the whole project, in order to reduce the management problems caused by poor multilateral coordination. In addition, in figure 3 can be found in the work mainly involves two parties, namely, management personnel and the personnel, the base and participants technology constitute joint debugging, head of the project management, coordination and administration, on the whole project for the mutual relations as shown in figure 3 :

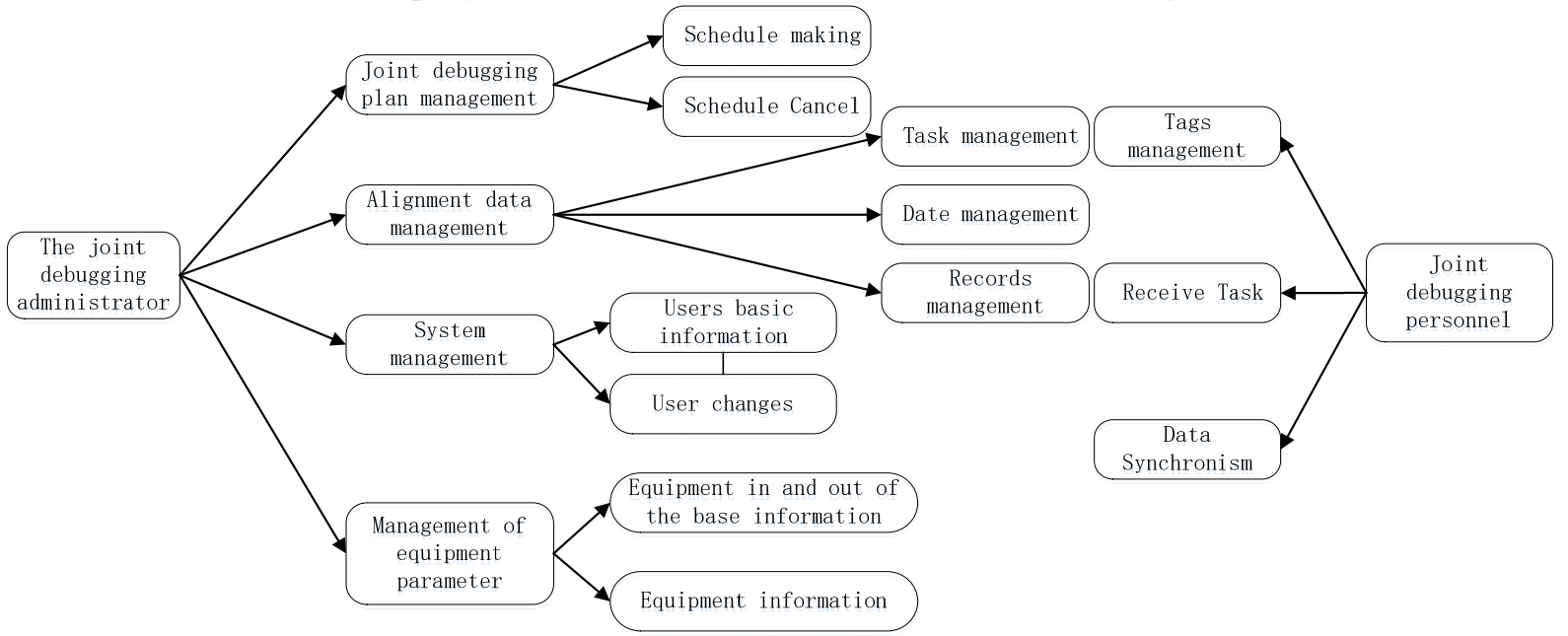

Fig.3 Debugging system diagram

In the allocation of responsibility, the management of the project management manager is responsible for planning, alignment of data management, system management, equipment parameter management tasks, an overall understanding of the situation of the project, for personnel assigned tasks, monitoring task completion, commissioning quality problem; Debugging personnel management task in strict accordance with the requirements of intelligent substation system debugging work, guarantee the normal work.

\subsection{Specific operation points}

(1) Tags management

To realize intelligent substation joint debugging test link of RFID technology, information integration requires RFID hardware and software realization, the management of the equipment label is the foundation of all radio frequency technology, so the intelligent substation joint debugging test before work should complete the RFID tags, the binding of the RFID tag well tied to reconciliation. Tags management is a one-to-one relationship with the label complete equipment, the equipment and the relationship between the tags before joint debugging to set up, in order to ensure the normal transmission of joint debugging information.

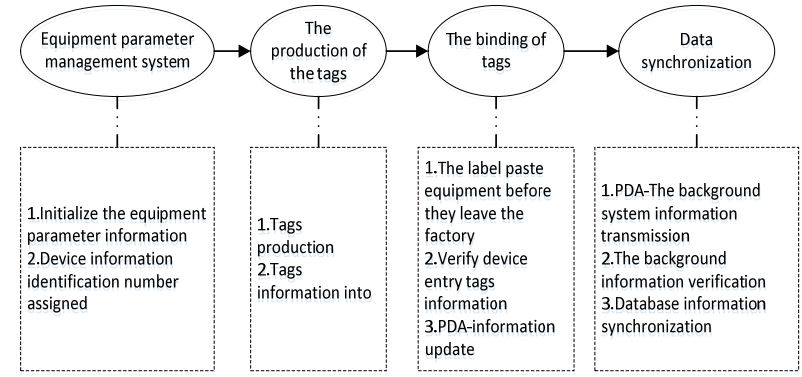

Fig.4 Tags management process 
The entire tags management process can be divided into the background management system of equipment parameter management system operation, label production, label the binding, data synchronization of four links.

(2) Task management

Task management is the most important part of the management mode. Before the start of the joint debugging by managers in the background management system to complete planning, coordinate management meeting, negotiating issues such as work task allocation, then completed by base management in data management, head of the task assignment; Participate in technical staff by handheld PDA terminal labor to testify the respective tasks and tasks relevant specifications, technical instruction, etc. The specific process as shown in figure 5:

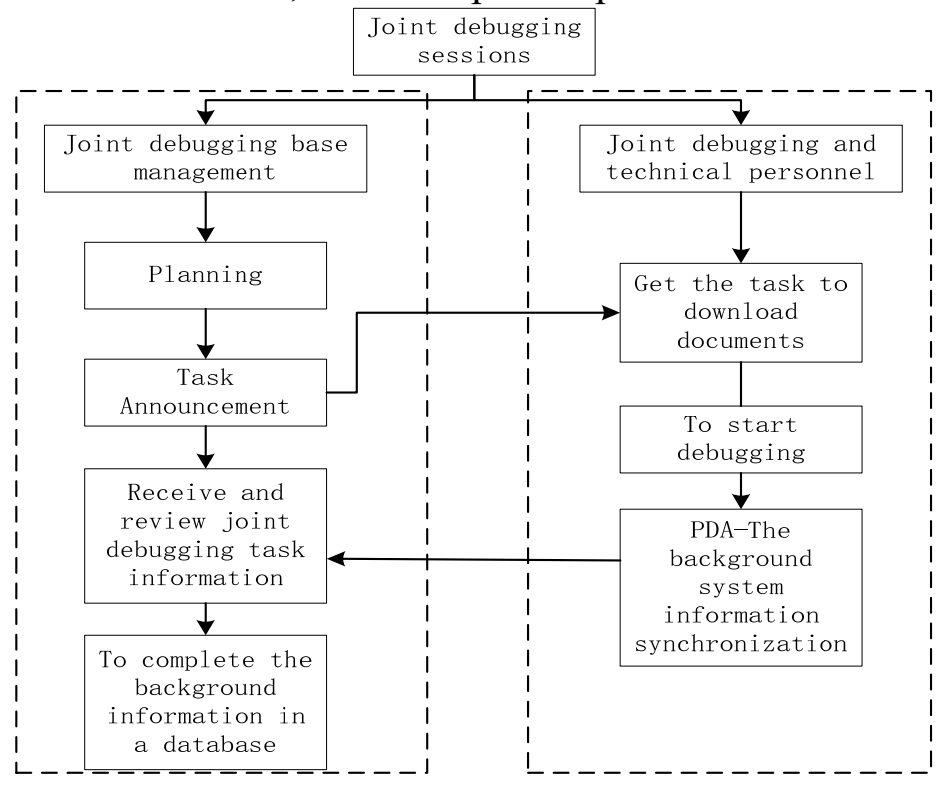

Fig. 5 Task management process

Base management personnel to participate in the joint debugging personnel management system in the background task allocation, accomplish the task assigned to the people, nobody is clear. Alignment after technical personnel to be present with the RFID tag id in the handheld PDA terminal downloads and operating instructions. If you want to achieve the purpose of strict control of schedule management, embedded concrete steps to task allocation of time, and technical personnel in strict accordance with the instructions and arrange task for debugging, each complete a confirmation in the PDA, prevent leakage key by mistake.

(3) The data synchronization

Data synchronization is the key of the alignment management work, alignment information collecting form mainly has two parts, alignment information data and verify the issuance of the background management system, handheld mobile PDA download and upload information. And background management system to participate in the debugging information with the base of the technical staff of handheld PDA mobile terminal information is not independent of each other, but through the transmission of information, information integration for information flow to form a closed loop between the two back, its information flow as shown in figure 6:

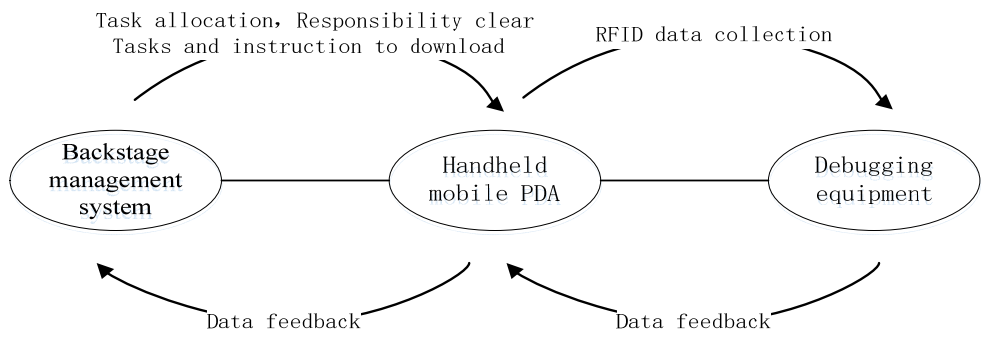

Fig.6 Debug the corresponding data and information in different stages of the closed loop flow 
Combined with figure 3, figure 6 can be found in the process of intelligent substation base joint debugging, background management system is controlled by management, to establish and cancel to the task, data management, system management and equipment parameter data management and technical personnel through hand-held mobile PDA download alignment tasks and the instruction, conduct joint debugging, handheld PDA debugging device of RFID information collection, the data stored in the database, the handheld terminals and upload the data by debugging personnel feedback to the background management system, management personnel check alignment data, update the background database and the data review, so that to complete the whole process of joint debugging RFID information flow.

(4) Database applications

Intelligent substation system is one of the purposes of joint debugging in the early stage of the intelligent device debugging phases through file configuration information collection, form a database, for the whole life cycle of intelligent substation equipment management provide powerful data support.

To record the state of equipment in the process of the intelligent substation alignment, the debugging process, the active RFID tags attached in intelligent substation equipment, active record alignment equipment status, writes it to the RFID tags, and uploaded to the backend database, as shown in figure 7.Such background database or purchase equipment from transportation to alignment at various stages of the data, forming machine through the information, including equipment name, location, the equipment type installation, debugging time, debugging time and debug the problem record information. Late for commissioning and provide experience for similar equipment debugging data, technical personnel can use permission to directly obtain the required information in the database, improve the work efficiency. As construction process, rich database, establishing database of whole life cycle of equipment information, provide convenience for equipment management.

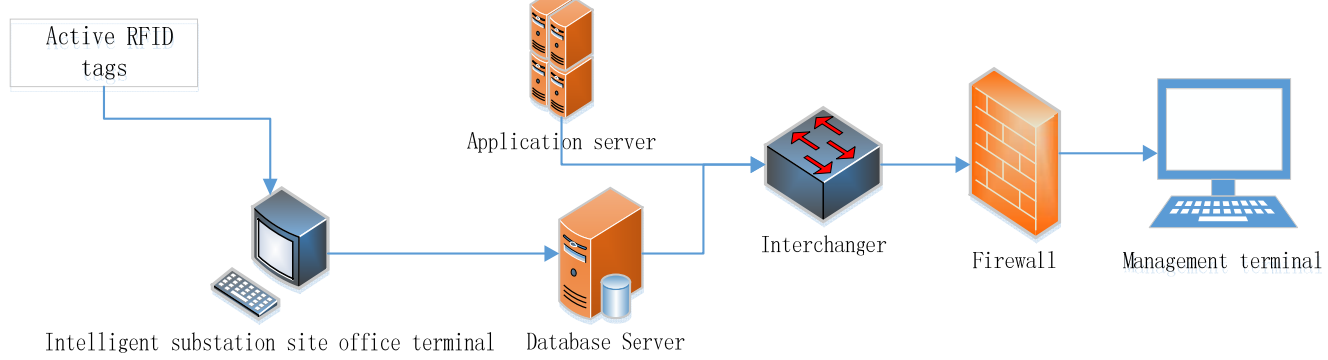

Fig.7 The flow chart of information integration

\section{Application value}

Because the cause of intelligent substation system joint debugging stage is various and complex, so the lifecycle management model based on the RFID information integration degree for the solution of these problems have different table 2 simple lists now joint debugging problems existing in the process of intelligent substation system, analysis application based on RFID information integration management mode after the problem solved. 
Tab.2 Pattern using problem solving degree after contrast analysis table

\begin{tabular}{|c|c|c|c|}
\hline Numble & Existing problems & Application of new management mode & $\begin{array}{l}\text { Solved } \\
\text { degree }\end{array}$ \\
\hline 1 & $\begin{array}{l}\text { Multilateral } \\
\text { coordination } \\
\text { problem is serious }\end{array}$ & $\begin{array}{l}\text { Independent management organizational structure, } \\
\text { coordination of management to improve the level of the } \\
\text { communication of the participants on the alignment of } \\
\text { the clear in liability and accountability }\end{array}$ & 1 \\
\hline 2 & $\begin{array}{l}\text { Equipment present } \\
\text { time difficult to } \\
\text { control }\end{array}$ & $\begin{array}{l}\text { Application of RFID technology in combination with the } \\
\text { Internet of things technology and GIS technology, } \\
\text { real-time tracking equipment transportation situation }\end{array}$ & 2 \\
\hline 3 & $\begin{array}{c}\text { Technical staff } \\
\text { have different level }\end{array}$ & $\begin{array}{l}\text { Set intelligent substation alignment technology } \\
\text { personnel qualification standard, improve the level of the } \\
\text { technician level, to achieve designed station personnel }\end{array}$ & 1 \\
\hline 4 & $\begin{array}{l}\text { Low degree of } \\
\text { information } \\
\text { integration }\end{array}$ & $\begin{array}{l}\text { Create alignment database, the detection of alignment } \\
\text { process, continuously updated database }\end{array}$ & 1 \\
\hline 5 & Process formalized & $\begin{array}{l}\text { The supervision of strict supervision and management } \\
\text { system, complete information }\end{array}$ & 2 \\
\hline
\end{tabular}

Note: 1, 2, 3, to express the degree of solution 1 - all solution; Part 2 - to solve; 3 - can't solve

Due to the lifecycle of the application based on RFID information integration management mode, can realize the online task allocation, task real time monitoring of the implementation of strict qualification examination level control, powerful database as support, in the process of joint debugging complete database data updated in real time, implement the data information integration, so the management mode in strict accordance with the requirements of, question 1, 3, 4 can all solution. However, the new management mode is not everything. There will be many other unforeseen obstacles, such as human factors, equipment transportation and debugging work quality are greatly influenced by artificial factors, therefore, to solve problem 2, part 5.Believe in the continuous development of technology and the management pattern, the intelligent substation joint debugging test link will constantly improve the management level.

\section{Conclusion}

By reference information integration based on RFID technology and the concept of whole life cycle management in the smart substation base joint debugging based on RFID is proposed on the basis of whole life cycle of information integration management mode, this paper analysis based on the RFID information integration of the whole lifecycle management mode, the advantages of making intelligent substation system joint debugging project management mode to achieve the optimal. Through the research, in this paper, the main conclusions are as follows:

(1) Based on RFID was introduced in whole life cycle of information integration of power management techniques;

(2) Combining with the characteristics of intelligent substation joint debugging and build the lifecycle management model based on the RFID information integration, the emphasis on the application of this model premise, organization form and the main points of the model under the specific operation to the attention of the problem;

(3) Based on the lifecycle management model based on the RFID information integration in the label management, task management, data synchronization, four aspects the interpretation of the database application, this paper introduces the concrete operation points in the process of the model in the application;

(4) Analysis of the application value of the new management mode for intelligent substation joint debugging test provide reference for the selection of project management mode 


\section{Acknowledgments}

Corresponding author: Chenglei, Sun.(277129298@qq.com)

\section{References}

[1] Song Y. Application of RFID in Information Management of Electric Power Equipment Based on Android [J]. International Journal of Sciences, 2016, 2(1):9-11.

[2] Chun-Xiao L I, Gao B, Bao-Gang L I. The Solutions of Substation Intellectual Management Based on RFID Technology [J]. Shanxi Electric Power, 2014.

[3] Xu H B, Liu J H, Jia X. Substation Inspection System Based on RFID Technology[J]. Advanced Materials Research, 2013, 734-737:2846-2850.

[4] Wang C X, Liu Y K, Wang H J, et al. Research and Application of Management System for Substation Asset Based on RFID[J]. Advanced Materials Research, 2012, 616-618:2111-2116.

[5] Cheng H Q, Qian P, Wu M C, et al. Information Management System of Smart Substation Electrical/Optical Cables Based on RFID Technology[J]. Applied Mechanics \& Materials, 2014, 568-570(568-570):1850-1855.

[6] Hu Z, Wang Y, Li X, et al. Research and utilization on RFID label in substation inspection[M]// Cloud Computing. Springer International Publishing, 2015:232-239.

[7] Zou D Y, Cai M, Chen F, et al. The Application of RFID and Two-Dimensional Bar Code in Substation Inspection [M]// Cloud Computing. Springer International Publishing, 2015:197-203.

[8] Navarro W, Ternera Y, Velez J C, et al. RFID system on electrical substation equipment[C]// IEEE, International Conference on Environment and Electrical Engineering. IEEE, 2015:15-20.

[9] Yan B, Yu W. Application of RFID Technology in Electric Power Patrol Inspection[C]// International Seminar on Future Biomedical Information Engineering. IEEE, 2008:239-242.

[10] Yang T Y, Hsu W H, Huang H C. PLANAR ANTENNA HAVING RFID ELECTRIC TAGS:, US20120126016[P]. 2012. 